\title{
A comparison of land use change accounting methods: seeking common grounds for key modeling choices in biofuel assessments
}

de Bikuna Salinas, Koldo Saez; Hamelin, Lorie; Hauschild, Michael Zwicky; Pilegaard, Kim; Ibrom, Andreas

Published in:

Journal of Cleaner Production

Link to article, DOI:

10.1016/j.jclepro.2017.12.180

Publication date:

2018

Document Version

Peer reviewed version

Link back to DTU Orbit

Citation (APA):

de Bikuna Salinas, K. S., Hamelin, L., Hauschild, M. Z., Pilegaard, K., \& Ibrom, A. (2018). A comparison of land use change accounting methods: seeking common grounds for key modeling choices in biofuel assessments. Journal of Cleaner Production, 177, 52-61. https://doi.org/10.1016/j.jclepro.2017.12.180

\section{General rights}

Copyright and moral rights for the publications made accessible in the public portal are retained by the authors and/or other copyright owners and it is a condition of accessing publications that users recognise and abide by the legal requirements associated with these rights.

- Users may download and print one copy of any publication from the public portal for the purpose of private study or research.

- You may not further distribute the material or use it for any profit-making activity or commercial gain

- You may freely distribute the URL identifying the publication in the public portal 


\title{
1 A comparison of land use change \\ 2 accounting methods: seeking common \\ 3 grounds for key modeling choices in \\ 4 biofuel assessments
}

\author{
Koldo Saez de Bikuña ${ }^{1 *}$, Lorie Hamelin ${ }^{2}$, Michael Zwicky Hauschild ${ }^{3}$, Kim Pilegaard ${ }^{1}$, Andreas \\ $\operatorname{Ibrom}^{1 *}$.
}

${ }^{1}$ DTU Environment, Atmospheric Environment section. Bygningstorvet 115, 2800 Kgs. Lyngby, Denmark.

$6 \quad{ }^{2}$ Hamelinlab, 173 Chemin de la Salade Ponsan, 31400 Toulouse, France.

$7 \quad{ }^{3}$ DTU Management, Quantitative Sustainability Assessment division. Produktionstorvet 424, 2800 Kgs.

8 Lyngby, Denmark.

$9 \quad{ }^{*}$ Correspondence to: koldodobikuna@hotmail.com

\section{Abstract}

Five currently applied methods to account for the global warming (GW) impact of the land-use change (LUC) induced greenhouse gas (GHG) emissions have been applied to four biofuel case studies. Two of the investigated methods attempt to avoid the need of considering a definite occupation -thus amortizationperiod by considering ongoing LUC trends as a dynamic baseline. This leads to account for a small fraction $(0.8 \%)$ of the related emissions from the assessed LUC, thus their validity is disputed. The comparison of methods and contrasting case studies illustrated the need of clearly distinguishing between the different time horizons involved in life cycle assessments (LCA) of land-demanding products like biofuels. Absent in ISO standards, and giving rise to several confusions, definitions for the following time horizons have been proposed: technological scope, inventory model, impact characterization, amortization/occupation, plantation lifetime and harvesting frequency. It is suggested that the anticipated technical lifetime of biorefineries using energy crops as feedstock stands as the best proxy for the cut-off criterion of land's occupation period, and 
thus for the amortization and inventory modeling periods. Top-down LUC models are suggested as a gross reference benchmark to judge LUC results from bottom-up models, since the former represent average GHG emissions from deforestation statistics at different spatial resolutions. Reporting LUC emissions per area and implementing a corporate accounting system that ascribes deforestation emissions to responsible companies could avoid the critical uncertainty related to yield estimations.

Keywords: land use changes, biofuels, life cycle assessment, time horizons, dynamic baseline method, reference system for LUC.

\section{Highlights}

- The technical lifetime of biorefineries is suggested as a technical and empirical metric for determining the long-term occupation of the used land. This, in turn, can be the basis to determine the amortization (if applied) and inventory modeling periods.

- The validity of current dynamic baseline methods to account for GHG emissions from LUC is disputed.

- Top-down LUC models represent average GHG emissions from deforestation which can be used as a gross reference to assess the validity of bottom-up LUC model results.

\section{Introduction}

After the European Union (EU) and the United States (US) established legal requirements for minimum biofuel use several years ago (European Commission, 2009; U.S. Congress, 2005), land-use change (LUC) emission accounting at the product level opened up the biofuels' box of Pandora (Fargione et al., 2008; Searchinger et al., 2008). The guidelines of the Intergovernmental Panel on Climate Change (IPCC) for national greenhouse gas (GHG) inventories (IPCC, 2006) were initially maladapted by several policies, as biogenic LUC emission were erroneously considered to be carbon neutral (Searchinger et al., 2009). The importance of this error was later reiterated and its implications for GHG accounting studies highlighted (Haberl et al., 2012). On the premise that only bioenergy from "additional biomass" can reduce GHG 
emissions, the use of food crops or arable land for bioenergy has been repeatedly questioned. This is because land-demanding bioenergy may induce the displacement of the previous agricultural production elsewhere (Haberl et al., 2012). Assuming that food (and generally land) demand will not decrease in the future, energy cropping ultimately leads to land expansion and intensification, i.e. indirect LUC (iLUC), inducing significant GHG emissions (Kløverpris, 2008; Schmidt et al., 2015). This leakage or iLUC effect has been addressed by many studies that focus on different biofuels and crop feedstock in different regions, like the ones assessing the US and the EU's biofuel policy implications (U.S. Environmental Protection Agency (EPA), 2010; Valin et al., 2015). The considered price-demand elasticities (i.e. how demand changes with price changes), future yields and other necessary modeling assumptions result in a wide range of iLUC emission factors (Plevin et al., 2015; Smith et al., 2014), which makes their implementation in policy-making difficult or even controversial (Finkbeiner, 2014). Several studies have proven the dominant role of LUC in determining the environmental performance of biofuels from a life-cycle perspective, thus their inherent uncertainty should be not be a reason to exclude them in environmental assessments (Muñoz et al., 2014; Plevin et al., 2010; Sanchez et al., 2012). Reported uncertainties rather point to an urgent need to further examine the key parameters that determine iLUC emissions (Plevin et al., 2015) to reduce results uncertainty (Li et al., 2016) and create consensus on key assumptions.

Life cycle assessment (LCA) is a standardized environmental assessment methodology (ISO, 2006a, 2006b), well-acknowledged and increasingly used to assess the environmental impact of biofuels and biofuel policies worldwide (U.S. EPA, 2010). One of the most critical key assumptions in LCA studies of land-based products is the amortization period used for LUC (Plevin et al., 2015), i.e. the time horizon over which the LUC emissions are linearly distributed for accounting. This is an artificial construct, which does not reflect the real GHG emission dynamics. Most policies regulating life-cycle GHG emissions of land-based products today recommend a 20 years period for amortization as recommended by the IPCC guidelines (BSI, 2011; European Commission, 2015; Greenhouse Gas Protocol, 2011; ISO, 2013). Since life-cycle results are typically given per functional output (e.g. per MJ for biofuel studies), reported LUC emissions (and the respective results) vary dramatically with the assumed amortization period (Kløverpris and Mueller, 2012) 
and estimated crop yields (Plevin et al., 2015). As an alternative, and to avoid the arbitrariness of a fixed amortization period, some life-cycle approaches have suggested taking a dynamic land-use baseline and proposed "amortization-free” LUC emission factors (Kløverpris and Mueller, 2012; Schmidt et al., 2015). Despite these significant efforts to model the environmental consequences from demanding additional land all over the world for growing various feedstocks (agricultural expansion in particular, but also intensification as in Tonini et al., 2016), there is a lack of research to identify the differences between the existing LUC accounting methods. Likewise, a need to distinguish the different time horizons involved in the LCA of land-demanding products has been identified.

Even though LUC are relevant for any land-demanding product, this study focuses on biofuels as they have received most of the scientific attention for decision-support in policy-making (European Commission, 2015; Haberl et al., 2010; U.S. EPA, 2010). Four different biofuel case studies have been selected to illustrate the induced LUC emission estimates that result from applying five different LUC accounting methods. Their differences are presented and the possibility of a common ground for the key amortization period assumption is investigated. The appropriateness of some methods is critically discussed, as well as the confusion around different time horizons in LCA and their relationship to biofuel assessments. The article concludes with the relevance of the analyzed methods for future LUC modeling and some potential policy implications.

\section{Methods}

\subsection{Time horizon definitions and LCA principles}

The ISO (ISO, 2006a) standards for LCA are based on the polluter-pays principle (Schwartz, 2005). This states that polluters are responsible for the environmental impairments they generate and hence, they need to compensate for the costs derived from reversing the harm. For LCA and environmental footprinting methods that take a life-cycle perspective, this translates into the obligation of accounting for all the emissions caused by the product along its entire life cycle. As a consequence, emission accounting methods such as the analyzed LUC models should strive for complying with the completeness, transparency, relevance and accuracy principles (Greenhouse Gas Protocol, 2011; ISO, 2006b). 
On the other hand, the ISO standards for LCA do not specifically define the different time horizons involved in a LCA. Therefore, some definition proposals are introduced here, as a prerequisite to advance in the conundrum around time horizons:

- Technological time scope: This time horizon is related to the life-cycle of the assessed product. It is part of the system boundary definition in the goal and scope phase (ISO, 2006a). When the assessed product or service requires the direct implementation of a producing technology (in the foreground system, e.g. a biorefinery plant), the technological time scope refers to the minimum anticipated lifetime of the technology over which the service or product is delivered.

- Inventory modeling period: This is the time horizon over which emissions are accounted, also referred to as 'analytical horizon' (Sanchez et al., 2012). In most cases, the inventory modeling period will end when the product reaches its end of life and is disposed of (and thus coinciding with the technological time scope). In some cases, long-term emissions may be expected, e.g. metal leaching from landfill (Hauschild et al., 2008) or LUC-induced peat oxidation (Valin et al., 2015). Such long-term emissions must be included within the system boundaries to comply with the completeness and accuracy accounting principles. For this, an extended inventory modeling period may be required (Bakas et al., 2015; Hauschild et al., 2008) which goes beyond the life cycle of the assessed product, and hence beyond the technological time scope of the LCA.

- Impact modeling period: This is the time horizon used by the impact assessment methods in the impact characterization step (ISO, 2006a); e.g. the time horizon used to calculate the global warming potential (GWP) of different GHG emissions. Due to the sensitivity of the impact score to the modeling period used in its characterization, it needs to be clearly stated for reporting purposes (ISO, 2006a). For example, if a 100 years horizon is used to report global warming (GW) impacts, the impact assessment method would be reported as $\mathrm{GWP}_{100}$.

In addition to the these time horizons that apply to any LCA, there are three other relevant periods for biofuel assessments (or other land-dependent products) that are involved: 
- Amortization period: Borrowed from financial accounting, the amortization period represents the assumed time horizon over which the assessed activity will take place and thus, the period over which the (environmental) investments need to be distributed (and possibly paid back). For landintensive products like dedicated biofuels, it refers to the period over which land is expected to be occupied for the production of the raw material.

- Harvesting frequency or single-rotation: refers to the time period between two consecutive harvests.

- Plantation lifetime or full-rotation: refers to the period between the planting and the final removal of a perennial crop plantation.

\subsubsection{Harmonization of applied time horizons}

While the impact modeling period to report GW impacts is rather homogeneous in literature (100 years by convention), the technological time scope is generally ignored and the inventory and amortization periods vary according to the case. In order to facilitate the comparison of different methods, the time horizons need to be harmonized based on the given definitions listed above

Energy crops like corn or sugarcane will be indeed replanted as long as they are demanded by fermentation plants to produce and supply bioethanol and/or bio-based products. Biorefineries and bio-based power-plants are necessarily inside the system boundaries of biofuel and bioenergy LCA, hence their technical lifetime stands as a more reasonable, robust and relevant criterion than any other arbitrary amortization period choice (European Commission, 2009). Despite still subject to the inherent political and economic uncertainties around the long-term operation of a plant, this criterion is commonly applied in industry to derive the economic viability of an investment. Albeit some uncertainty, the technical lifetime is based on material science, i.e. endurance of the components and materials, and empirical data from industries.

For the sake of simplicity, it was assumed that no peat land has been drained for the establishment of any plantation. This means that the technical criterion that determines the occupation period of land (and thus the amortization period) is also valid for determining the GHG inventory modeling period, since no long-term 
emissions are expected for these case studies. These and other aspects around long-term emissions are discussed in Section 4.1.1.

Table 1. Time horizons in the four study cases, according to the definitions and criteria presented in Section 2.1. All values are given in years

\begin{tabular}{|c|c|c|c|c|c|c|}
\hline $\begin{array}{l}\text { Biofuel study } \\
\text { cases }\end{array}$ & $\begin{array}{l}\text { Single } \\
\text { rotation }\end{array}$ & $\begin{array}{c}\text { Full } \\
\text { rotation }\end{array}$ & $\begin{array}{c}\text { Technological } \\
\text { scope }\end{array}$ & $\begin{array}{c}\text { Amortization } \\
\text { (occupation) }\end{array}$ & $\begin{array}{c}\text { Inventory } \\
\text { modeling } \\
\text { (GHG emissions) }\end{array}$ & $\begin{array}{c}\text { Impact } \\
\text { modeling } \\
\text { (GWP) }\end{array}$ \\
\hline $\begin{array}{l}\text { Willow } \\
\text { woodchips }\end{array}$ & 3 & 20 & 20 & 20 & 20 & 100 \\
\hline $\begin{array}{l}\text { Sugarcane } \\
\text { ethanol }\end{array}$ & 1 & 6 & 30 & 30 & 30 & 100 \\
\hline $\begin{array}{l}\text { Palm-oil } \\
\text { biodiesel }\end{array}$ & - & 25 & 30 & 30 & 30 & 100 \\
\hline Corn ethanol & 1 & 1 & 30 & 30 & 30 & 100 \\
\hline
\end{tabular}

\subsection{Biofuel study cases}

154 The used land area has been taken as the functional unit (FU) for this assessment (Cherubini et al., 2009;

155 Pawelzik et al., 2013). Reporting the LUC per demanded hectare $\left(\mathrm{ha}_{\mathrm{dem}^{-1}}{ }^{-1}\right)$ allows for estimating the resulting

156 GHG emissions independently of the related crop yields, thus avoiding the propagation of the inherent variability and uncertainty of yield estimates (Plevin et al., 2015) to the GHG emission estimates from LUC.

158

To cover a wide range of biofuel types, four energy crops from different regions of the world and with different plantation life-cycles were selected: oil-palm, short-rotation willow, sugarcane and corn (see Table 1). It was assumed that the oil-palm plantation was used for biodiesel and established on a Malaysian loggedover forestland (Wicke et al., 2008), the willow was gasified for cogeneration of heat and power (CHP) and established on Danish arable land (Saez de Bikuña et al., 2016), while the sugarcane and corn were used for ethanol production and were planted on Brazilian cropland (Lapola et al., 2010) and on US cropland (Plevin et al., 2010), respectively. The single- and full-rotation periods for Brazilian sugarcane were taken from Seabra et al. 2011. Following the criterion presented in 2.1.1, the most relevant occupation (i.e. amortization) periods were identified for each biofuel case: 30 years for the ethanol and biodiesel feedstock (as that is the expected lifetime of such biorefineries; Davis et al., 2013; U.S. EPA, 2010) and 20 years for willow CHP (both the lifetime of the plantation and that of a small cogeneration plant, Energinet, 2012; Saez de Bikuña et al., 2016). 


\subsubsection{Ad hoc LUC emission factors}

For comparison purposes (and since iLUC emissions cannot be directly measured), we take as reference value the LUC emissions estimated ad hoc by the authors (Lapola et al., 2010; Plevin et al., 2010; Saez de Bikuña et al., 2016; Wicke et al., 2008). The ad hoc LUC emissions were estimated with case-specific economic iLUC models (bottom-up) based on consequential LCA. These models predict the multiple economic effects related to supply-demand laws, such as product and co-products substitution, intensification and reduced (food/feed) demand, in order to get a final area expansion estimate from the initial demand shock. The LUC emission of the Malaysian palm-oil biodiesel represents only direct LUC, because the land clearing is assumed to take place directly on the native rainforest to establish the oil-palm plantation (Wicke et al., 2008).

For the Danish willow plantation, LUC emissions were taken from Table 2 (iLUC emissions) and soil C gains of $28.5 \mathrm{~kg} \mathrm{C} \mathrm{ha}^{-1} \mathrm{yr}^{-1}$ are considered (Methods section in the main text) based on Saez de Bikuña et al., 2016. For the Brazilian sugarcane plantation, LUC emissions were derived from the total carbon debt of sugarcane expansion (from $4224 \mathrm{Tg} \mathrm{CO}_{2} \mathrm{eq}$ and 13.6 Mha expansion, Figure 2, Lapola et al. 2010), which yielded a LUC emission factor of $311 \mathrm{Mg} \mathrm{CO}_{2} \mathrm{eq} \mathrm{ha}_{\mathrm{dem}}{ }^{-1}$. The LUC factor for corn ethanol was taken as the mean value of several studies $\left(62 \mathrm{~g} \mathrm{CO}_{2} \mathrm{MJ}^{-1}\right)$ and the average ethanol yield of 4000 liter ha ${ }^{-1}$ (Plevin et al., 2010). Taking a lower heating value (LHV) of $22.8 \mathrm{MJ} \mathrm{liter}^{-1}$ (Seabra et al., 2011), resulted in $169 \mathrm{Mg} \mathrm{CO}_{2} \mathrm{eq}$ $\mathrm{ha}^{-1}$. For the Malaysian oil-palm plantation, LUC emissions were calculated from the $\mathrm{C}$ stock data provided in Table 2 in Wicke et al. 2008. A logged-over rainforest with an above-ground vegetation of $175 \mathrm{Mg} \mathrm{DM}$ $\mathrm{ha}^{-1}$ was considered, which corresponds to $88 \mathrm{Mg} \mathrm{C} \mathrm{ha}^{-1}$. To this, a loss of $20 \mathrm{Mg} \mathrm{C} \mathrm{ha}^{-1}$ from the soil was added (Table 2, Wicke et al. 2008), which resulted in a total LUC estimate of $388 \mathrm{Mg} \mathrm{CO}_{2} \mathrm{ha}^{-1}$.

Temporary plant C-sequestration was neglected for corn, sugarcane (annually harvested) and willow (3-year

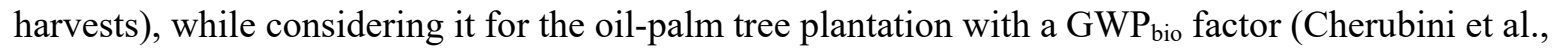
2011).Therefore, the permanent plant sequestration of $95 \mathrm{Mg} \mathrm{C} \mathrm{ha}^{-1}$ considered by Wicke et al. 2008 was converted to temporary $\mathrm{C}$-sequestration with a $\mathrm{GWP}_{\text {bio }}$ factor of 0.1 for a 100 years horizon and 26 years 
rotation period (Table 3 in Cherubini et al. 2011). Table 2 summarizes the values and key characteristics of the ad hoc LUC emission factors.

Table 2 Ad hoc LUC emission factors, their main characteristics and values.

\begin{tabular}{lccc}
\hline Energy crop & Model type & Value & Reference \\
& & $\left(\mathrm{Mg} \mathrm{CO}_{2} \mathrm{eq} \mathrm{hadem}^{-1}\right)$ & \\
\hline Willow & Bottom-up. GTAP model & 283 & Saez de Bikuña et al., 2016 \\
Sugarcane & Bottom-up. LandSHIFT model & 311 & Lapola et al. 2010 \\
Oil-palm & Direct LUC & 388 & Wicke et al. 2008 \\
Corn & Mean of several bottom-up models & 162 & Plevin et al. 2010
\end{tabular}

\subsection{LUC accounting methods}

Five different LUC accounting methods are taken to illustrate the variation of accounted LUC for each biofuel case per additional hectare demanded. The five accounting methods are explained in the following subsections and comprise of: $i$ ) a global average LUC emission factor that includes both expansion and intensification effects, $\mathrm{LUC}_{\text {global, }}$; two versions of a dynamic land-use baseline method: ii) $\mathrm{LUC}_{\mathrm{DBM} 1}$ and (iii) $\mathrm{LUC}_{\mathrm{DBM} 2} ; \mathrm{iv}$ ) the consequential variant of the GHG protocol method for accounting unknown LUC of products, $\mathrm{LUC}_{\mathrm{GHGP}}$; and $(v)$ the iLUC emission estimates computed for the last amendment to the European

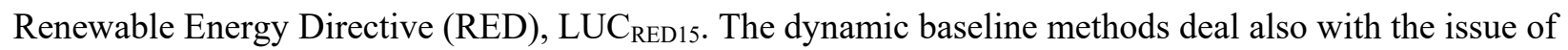
amortization and, indirectly, with the conundrum around time horizons (Kløverpris and Mueller, 2013). All of the methods lead to results that can be expressed in mass $\mathrm{CO}_{2} \mathrm{eq}$ emitted per hectare for all of the investigated cases.

\subsubsection{World-average LUC emissions: $L U C_{\text {global }}$ factor}

This top-down method, also called biophysical (Schmidt et al., 2015) or deterministic (Tonini et al., 2016; Warner et al., 2014), is used herein to calculate a generic $\mathrm{LUC}_{\text {global }}$ factor. This is based on previous work (Saez de Bikuña et al., 2016) and is fully described in the Supplementary Materials (SM) in Appendix A. This method provides a global average LUC emission factor representing the approximate effect of demanding one additional productive hectare to the global market. It is assumed that the land appropriation for energy cropping displaces certain food crop production, which is considered to be achieved through a combination of agricultural expansion and intensification processes. The share of each process is computed 
on the basis of time series analysis from global food production statistics (FAO stat database). The additional food production is thus achieved through agricultural land expansion and additional synthetic nitrogen fertilizer application in the respective (historical) proportions, thereby assuming linearity for future trends. Here, it is considered that $37 \%$ of the additional global food production is achieved through land expansion and 63\% through intensification (Saez de Bikuña et al., 2016), calculated on a wet basis (differently from the dry basis shares of $25 / 75 \%$ as taken in Tonini et al., 2016). Contrary to economic LUC models, other shortterm indirect effects like reduced food consumption (Valin et al., 2015) are disregarded, as it is assumed that the mid- and long-term food demand is not affected by short-term price changes (Schmidt et al., 2015). Since biofuel production periods (i.e. the explained occupation and amortization periods) will span over two or three decades (see Table 1), this is a powerful simplifying assumption which is considered to be valid under the logic of economic supply-demand laws. That is, as long as the production factors (for the price affected food/feed crops) are not constrained (and, in the light of development and within a productivist view, land is not yet a constraint), supply will follow demand insofar market price pays off production costs. As a result, the initial food shock demand is assumed to be fully satisfied in the mid- or long-term, i.e. within the duration of the assessed bioenergy systems. The resulting average $\mathrm{GHG}$ emissions included in the $\mathrm{LUC}_{\text {global }}$ factor are therefore $165.5 \mathrm{Mg} \mathrm{CO}_{2} \mathrm{eq} \mathrm{hadem}^{-1}$ (from agricultural expansion, which are amortized according to the suggested criteria, over the stated occupation periods; see 2.2) and $2.1 \mathrm{Mg} \mathrm{CO}_{2} \mathrm{eq} \mathrm{hadem}^{-1} \mathrm{yr}^{-1}$ (from additional intensification, which are added to annual emissions along the stated occupation periods), respectively (see Table A1). Emission credits from post-production substitution effects (e.g. distiller's dry grains with solubles (DDGS) from corn ethanol as a substitute of soymeal), can still be accounted for in a separate step to increase transparency. Therefore, reported emissions in $L U C_{\text {global }}$ do not include such casespecific secondary effects.

\subsubsection{Dynamic Baseline Methods}

Dynamic baseline methods assume that deforestation LUC as a consequence of the assessed product would otherwise have occurred anyway after one year, if the region has historical deforestation trends (Kløverpris and Mueller, 2012; Schmidt et al., 2015). This means that the studied crop is only ascribed the LUC emissions from deforestation corresponding to advancing them by one year. To calculate the reported 
emissions with dynamic baseline methods, we apply a time-discounted version of the Global Warming

246 Potential (GWP) factor to consider the time effect of anticipating LUC emissions by one year (Kløverpris

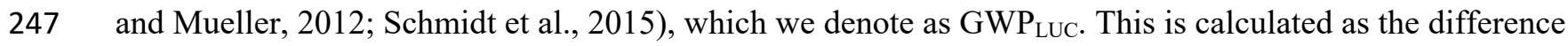
248 between the cumulated radiative forcing $(\mathrm{RF})$ of a $\mathrm{CO}_{2}$ pulse emission over 100 years and a $\mathrm{CO}_{2}$ pulse 249 emission over 99 years, divided by the cumulated $\mathrm{RF}$ of a reference $\mathrm{CO}_{2}$ pulse emission over 100 years 250 (Kløverpris and Mueller, 2012) (Figure 1). Because the emitted GHG is in both of the compared cases $\mathrm{CO}_{2}$, 251 the $\mathrm{GWP}_{\mathrm{LUC}}$ factor can be expressed with the cumulated residence in the atmosphere only and the radiative 252 efficiency cancels out (see Appendix B for a detailed description):

253

$G W P_{L U C}=\frac{\int_{0}^{100} R_{\mathrm{CO}_{2}}(t) d t-\int_{0}^{99} R_{\mathrm{CO}_{2}}(t) d t}{\int_{0}^{100} R_{\mathrm{CO}_{2}}(t) d t}$

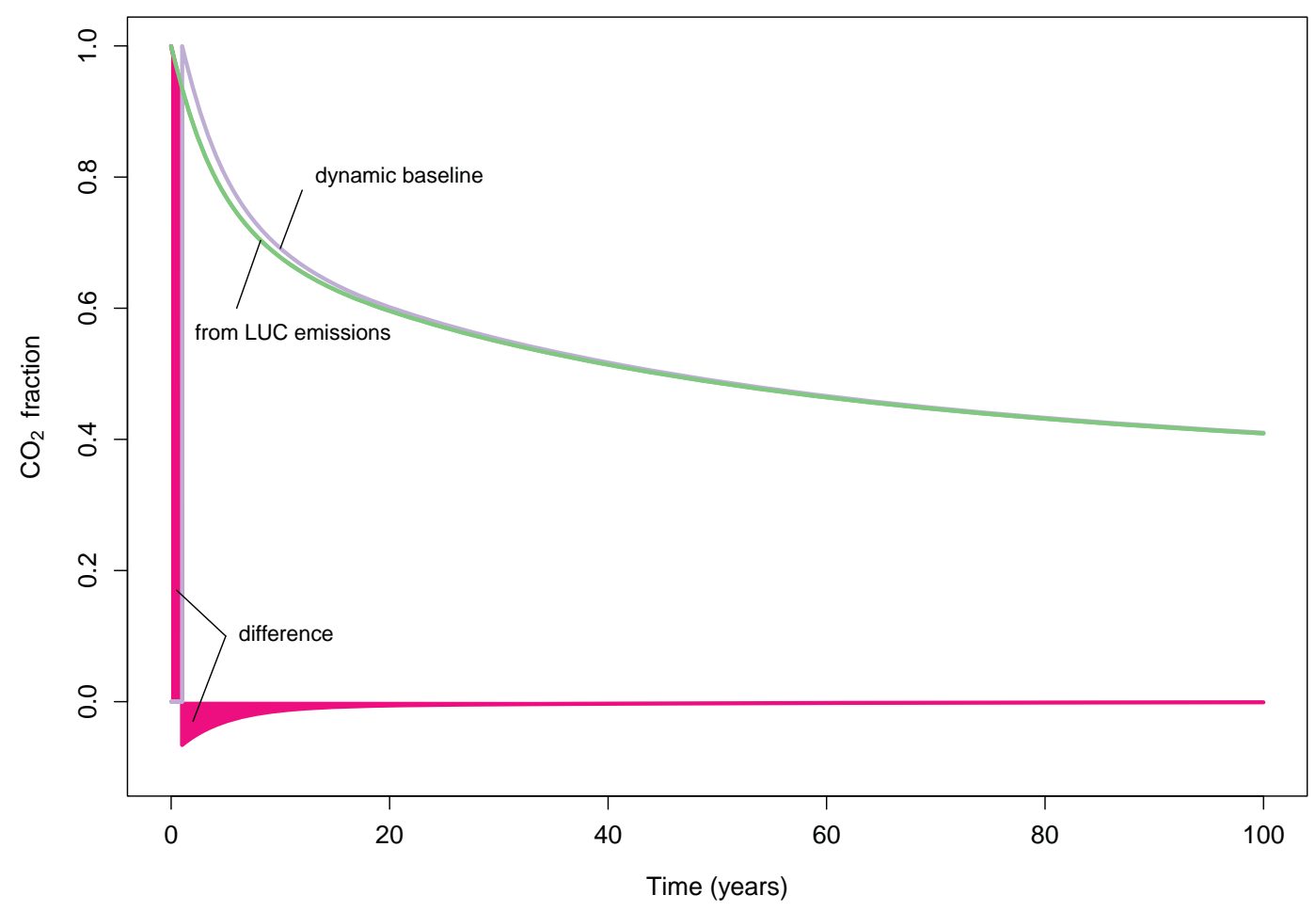

255 Figure 1 LUC emissions under dynamic baseline conditions. The $\mathrm{CO}_{2}$ fraction of a generic LUC emission (green) and 256 of the dynamic baseline (violet) over 100 years. In magenta the difference between them, $0.8 \%$, the value of the 257 GWP 
As earlier mentioned, two variants of the dynamic baseline method (DBM) are here considered. For the first variant (LUC $\left.\mathrm{LBM}_{\mathrm{DB} 1}\right), \mathrm{GWP}_{\mathrm{LUC}}$ is applied to the ad hoc LUC emission estimates of each case study, resulting in a one-time discounting of the respective $\mathrm{CO}_{2}$ emissions (Kløverpris and Mueller, 2012). For the second variant $\left(\mathrm{LUC}_{\mathrm{DBM} 2}\right), \mathrm{GWP}_{\mathrm{LUC}}$ is applied only to the $\mathrm{CO}_{2}$ emissions from the expansion share of the $\mathrm{LUC}_{\mathrm{global}}$ factor (i.e. 141.6 $\mathrm{Mg} \mathrm{CO}_{2} \mathrm{ha}_{\mathrm{dem}^{-1}}{ }^{-1}$ s see Table A1), which results in $1.1 \mathrm{Mg} \mathrm{CO}_{2} \mathrm{ha}_{\mathrm{dem}}{ }^{-1}$. However, the LUC $\mathrm{DBM}_{\mathrm{DB}}$ does not consider land expansion emissions as a single $\mathrm{CO}_{2}$ release that happens at the beginning of the project with the establishment of the energy crop, but rather as part of an existing annual trend (Schmidt et al., 2015). Consequently, the considered LUC emissions in $\mathrm{LUC}_{\mathrm{DBM} 2}$ are the sum of two global average, annual GHG emission factors that correspond to land expansion $\left(1.1 \mathrm{MgCO}_{2} \mathrm{hadem}^{-1} \mathrm{yr}^{-1}\right)$ and intensification (2.1 $\mathrm{Mg} \mathrm{CO}_{2} \mathrm{eq} \mathrm{hadem}{ }^{-1} \mathrm{yr}^{-1}$ ) effects. This results in a total of $3.2 \mathrm{Mg} \mathrm{CO}_{2} \mathrm{eq} \mathrm{hadem}^{-1} \mathrm{yr}^{-1}$ that are added to other GHG emissions in the biofuel production during the different occupation periods.

\subsubsection{The GHG Protocol method}

The LUC accounting method of the GHG protocol ( $\mathrm{LUC}_{\mathrm{GHGP}}$ ) is the one explained in Annex B.2 of the product life-cycle accounting standard (Greenhouse Gas Protocol, 2011), used to estimate average LUC in products of unknown land-use and origin. In a nutshell, $\mathrm{LUC}_{\mathrm{GHGP}}$ is a country-specific version of the $\mathrm{LUC}_{\text {global }}$ top-down model excluding intensification emissions. That is, it represents the country-average LUC emissions of demanding one additional hectare of the assessed crop (known or assumed to originate from that country). Consequently, this method is only valid to estimate LUC emissions of crops that originate (knowingly or presumably) from countries where deforestation is ongoing (i.e. Malaysia and Brazil). Indirect LUC emissions that may arise from energy cropping in US (corn) and Denmark (willow) were therefore not accounted with this method. Land-use area cover statistics from FAO stat database (2003 to 2014) are taken, considering only the new areas converted to the respective plantations (oil-palm or sugarcane). This is the consequential variant of the method, different from a possible attributional variant which would take the whole existing plantation area in the country to compute an average LUC emission factor instead (Milà i Canals et al., 2012). See Appendix C for additional details. 


\subsubsection{LUC emission factors from the amended RED directive}

In the last RED average LUC emission factors per crop group (e.g. sugar crops, oil crops, etc.) are reported in $\mathrm{g} \mathrm{CO}_{2}$ eq $\mathrm{MJ}^{-1}$ (Appendix V, European Commission 2015). For a better comparison, the crop-specific LUC emission results were taken from the original report (Chapter 4, Valin et al. 2015), with non-amortised results given in tonnes $\mathrm{CO}_{2} \mathrm{eq} \mathrm{hadem}{ }^{-1}$. Short rotation woody crops are excluded in the amended RED of 2015 though. Being their current demand and supply marginal, related global LUC from scaling up their demand was not simulated with the agro-economic model implemented (GLOBIOM). Hence LUC emissions could not be calculated with this method for the willow case study. See calculation details in Appendix D. In Table 3 a summary of the five LUC methods is presented with their main features.

Table 3. Summary of main characteristics of the LUC methods applied in this study.

\begin{tabular}{|c|c|c|c|c|}
\hline LUC method & Model type & Expansion & Intensification & Amortization \\
\hline LUC global & Top-down. Global average & Yes & Yes & Yes $^{\alpha}$ \\
\hline $\mathrm{LUC}_{\mathrm{DBM} 1}$ & Ad hoc $\mathrm{LUC} \times \mathrm{GWP}_{\mathrm{LUC}}$ factor & Yes & No & No \\
\hline $\mathrm{LUC}_{\mathrm{DBM} 2}$ & $\mathrm{LUC}_{\text {global }} \times \mathrm{GWP}_{\text {LUC }}$ factor & Yes & Yes & No \\
\hline $\mathrm{LUC}_{\mathrm{GHGP}}$ & Top-down. Regional average & Yes & No & Yes $^{\alpha}$ \\
\hline $\mathrm{LUC}_{\mathrm{RED} 15}$ & Bottom-up. GLOBIOM model & Yes & Yes* & $\mathrm{Yes}^{\mathrm{a}}$ \\
\hline
\end{tabular}

* Yield improvement, substitution and reduced demand effects considered for the calculation of final expansion, but intensification emissions not included. ${ }^{\alpha}$ Amortization according to the criterion presented in Section 2.1 (see Table 1).

\section{Results}

Taking the ad-hoc LUC emissions as reference, it is seen that the top-down approach $\mathrm{LUC}_{\text {global }}$ gives the closest LUC estimates (underlined in Table 4), followed by the LUC $_{\text {GHGP. }}$ The latter, despite having a higher spatial resolution than $\mathrm{LUC}_{\text {global, }}$, showed the highest emission estimates of all methods. This may be explained by the exclusion of intensification effects in its calculation. Remarkably, the country-average LUC $_{\mathrm{GHGP}}$ emissions estimate for the oil-palm case is similar to the representative case of secondary rainforest clearing emissions, both LUC estimates having excluded peat oxidation and intensification emissions.

$\mathrm{LUC}_{\text {global }}$ estimates were $28 \%$ lower, $27 \%$ lower and $34 \%$ higher than the willow, sugarcane and corn references, respectively. If we exclude the (otherwise intrinsic) intensification emissions from the $\mathrm{LUC}_{\text {global }}$ factor (i.e. only considering $165.5 \mathrm{Mg} \mathrm{CO}_{2} \mathrm{eq} \mathrm{hadem}^{-1}$, see section 2.3.1) to harmonise it with the ad-hoc LUC for the US corn ethanol case, the two estimates differ by only $2 \%$. 
The accounted $\mathrm{LUC}_{\mathrm{RED} 15}$ emissions were systematically lower than the reference ad hoc LUC estimates and

307 the top-down emission factors. The reasons behind this are the included short-term effects (e.g. $42 \%$

308 reduction of palm-oil demand), the high C-sequestration assumptions in soil and biomass (e.g. as much as

$30962 \%$ of the total $\mathrm{CO}_{2}$ eq emissions from LUC for sugarcane) and the embedded substitution effects in corn

310 ethanol ( $26 \%$ of new land demand covered by DDGS substitution, while $18 \%$ of feed demand is reduced), as

311 stated in Valin et al. 2015.

312 On the other hand, the $\mathrm{LUC}_{\mathrm{DBM} 1}$ applies a one-time, absolute discounting of $99.2 \%$ (the GWP $\mathrm{PUC}_{\text {) }}$ to the $\mathrm{ad}$

313 hoc LUC emissions, which explains its great deviation respect to any other method. The $\mathrm{LUC}_{\mathrm{DBM} 2}$ applies the

314 same discounting to the share of (annual) agricultural expansion in the $\mathrm{LUC}_{\text {global }}$ factor, which summed over

315 the predicted occupation period results in moderate estimates (yet significantly lower than the ad hoc

316 references and the other top-down factors). Even though each DBM accounts for LUC emissions in a

317 different manner, they apply the same discounting logic. As a result, LUC emissions from agricultural

318 expansion in both DBM were consistently and significantly lower than any other method. The logic of DBM

319 methods and its validity are discussed in section 4.2.

Table 4. GHG emission accounting of LUC with different methods for the four biofuel study cases. Underlined the LUC estimates closest to the ad hoc LUC estimates. DK stands for Denmark, BR for Brazil, MY for Malaysia, NA for not accounted. See Sections 2.2 and 2.3 for calculation methods.

Accounted LUC GHG emissions ( $\left.\mathrm{Mg} \mathrm{CO}_{2} \mathrm{eq} \mathrm{hadem}{ }^{-1}\right)$

\begin{tabular}{lcccccc}
\hline Energy crops & Ad hoc LUC & LUC DBM1 & LUC DBM2 & LUC $_{\text {global }}$ & LUCGHG & LUC \\
\hline $\begin{array}{l}\text { Willow } \\
\text { (DK cropland) }\end{array}$ & 283 & 2 & 63 & $\underline{206}$ & NA & NA \\
$\begin{array}{l}\text { Sugarcane } \\
\text { (BR cropland) }\end{array}$ & 311 & 4 & 95 & $\underline{226}$ & 428 & 43 \\
$\begin{array}{l}\text { Oil-palm } \\
\text { (MY forest) }\end{array}$ & 388 & 5 & 79 & 216 & $\underline{428}$ & 211 \\
$\begin{array}{l}\text { Corn } \\
\text { (US cropland) }\end{array}$ & 169 & 1 & 95 & $\underline{226}$ & NA & $12^{\dagger}$ \\
\hline
\end{tabular}




\section{Discussion}

\subsection{Time horizons in LCA of biofuels}

Different time horizons coexist in LCA of biofuels. The main problem related to them may be their lack of definition in the LCA standards (BSI, 2011; ISO, 2013, 2006a, 2006b). As a result, most practitioners are unaware of i) their differences, ii) the implicit assumptions done when carrying out a LCA, and iii) the mixed effects they may have on results. For example, in an LCA of a willow plantation, these time horizons can potentially overlap each other. The technological time scope would be here the lifetime of a small-scale cogeneration plant (Energinet, 2012), if it is used for CHP, coinciding with the expected plantation lifetime of 20 years (Saez de Bikuña et al., 2016). This time horizon would again coincide with the 20 year amortization for LUC prescribed in the IPCC guidelines (IPCC, 2006) and most LCA regulations (BSI, 2011; European Commission, 2009; ISO, 2013; The Greenhouse Gas Protocol, 2006). If the plantation is established on a normal arable or grassland where no long-term emissions are expected beyond the 20 year rotation period, the inventory modeling period would be the same as the previous time horizons (20 years). Finally, a 20-year impact modeling period could be picked to calculate the relevant GW impacts (i.e. $\mathrm{GWP}_{20}$ ), when really short-term effects are to be represented (in this case over the next two decades only; UNEP/SETAC Life Cycle Initiative, 2016). But these time horizons can also be different from each other (and most often are). For example, a 'farm-to-gate' LCA of a land-based product may stick to the crop lifetime (e.g. six year for a sugarcane plantation) to define the expected occupation period (Seabra et al., 2011), since there is no power-plant or biorefinery inside the system boundaries. If the crop is established on a drained peatland, there will be GHG emissions beyond the crop's lifetime which need to be accounted. This would result in four different time horizons: a 6 year occupation period, an arbitrary 20 year amortization period (according to most regulations), an extended inventory modeling period (e.g. 50 years, Valin et al., 2015) to account for the long-term peat oxidation and an arbitrary impact modeling period to calculate the GW impact (e.g. 100 years, i.e. $\mathrm{GWP}_{100}$ ).

These two examples illustrate the conundrum around time horizons in LCA of biofuels. If these time horizons are properly distinguished, extending the inventory modeling period to account for long-term 
emissions (e.g. peat oxidation) in biofuel LCAs would not imply extending its amortization period (Valin et al., 2015). This is because, as it has been argued, the technical basis for amortization is the lifetime of the involved technology, which is independent from any author's subjective standpoint. Therefore, according to our definition proposals, including long-term emissions in LCA of biofuels established on peat land would increase the annualized LUC emissions (and related GW impacts), not decrease them (Valin et al., 2015). Likewise, changes in SOC and foregone C-sequestration (which are caused by cultivation) need to be considered for the identified inventory modeling period (which is the expected occupation period given by the amortization criterion established in Section 2.1), not less (U.S. EPA, 2010). In this respect, the 30 years amortization choice stands not as an arbitrary one (Plevin et al., 2015), but as an engineering and financial criterion generally applied in industry. On the other hand, the full-rotation period of tree cultivars could be a better estimate of the transformed land's long-term occupation in forestry systems (as it would represent the minimum commitment period of the responsible company). But forestry systems are multi-output systems which companies optimize according to market price of different products, 'bioenergy' being more often a by-product (Cintas et al., 2015), unlike the agricultural study cases analyzed herein.

It is thus evident that defining and distinguishing the time horizons mentioned in Section 2.1 is a prerequisite to perform biofuel LCAs in a more transparent and consistent way. Nevertheless, the choice of the applied modeling periods for the characterization of (e.g. GW) impacts may be done by convention (e.g. $\mathrm{GWP}_{100) \text {, }}$ but remains arbitrary as it implies value judgements over the importance given to short-term and long-term (GHG) emissions (Brandão and Canals, 2012). GHG inventories can be though discretized in annual steps and be combined with dynamic characterization factors to calculate time-adjusted GW impacts (Levasseur et al., 2010; O'Hare et al., 2009), which would be the most accurate solution to deal with LUC and other lifecycle GHG emissions of land-demanding products. These methods were developed to avoid the bias of traditional LCA, where all life-cycle emissions are summed up and the GWP is calculated from the aggregated score (i.e. all emissions are assumed to occur in the first year). These methods were not applied in this study because it focused exclusively on LUC and not the total life-cycle emissions. 


\subsubsection{Long-term emissions and post-occupation LUC in biofuel assessments}

Post-occupation LUC may be also considered (also referred to as post-cultivation LUC, Sanchez et al. 2012). These can be confused with 'pure' long-term emissions though. While 'pure' long-term emissions from the slow decay of previously accumulated organic matter (e.g. peat oxidation) start with the establishment of the biofuel project (and may continue for decades Fargione et al. 2008; Valin et al. 2015), post-occupation LUC emissions start at the end of the biofuel project, when the biorefinery or power-plant is no longer in operation. These will be thus the result of future human land-use activities on the released land (e.g. natural regeneration, if the land is abandoned). This differentiation is important because physical or 'pure' long-term emissions in dedicated biofuel LCAs regard almost exclusively energy crop plantation establishments on drained peat land, which mainly take place in Indonesia and Malaysia (Valin et al., 2015). On the contrary, post-occupation LUC emissions may apply to any biofuel (and land-demanding product), while being completely determined by the global (or regional) land market and land-use trends at the end of the identified amortization (i.e. occupation) period. Since "land use after 30 years is highly uncertain and there is no guarantee of future rotations" (U.S. EPA, 2010), the exclusion of post-occupation LUC (which are emissions from future human land-uses) in dedicated biofuel LCA seems desirable. When post-occupation LUC assumptions are unavoidable in biofuel LCA (e.g. regarding the fate of oil-palm trees at the end of the occupation), practitioners should depict key choices as different scenarios and/or test them in a sensitivity analysis. Most energy crops are nonetheless entirely harvested to obtain the final biofuel product. This is the case for all the starch-rich and sugar crops used to produce ethanol, annual oil crops to produce biodiesel (Reijnders and Huijbregts, 2008) and short-rotation perennials like willow, poplar, switchgrass or miscanthus to produce biomass for energy purposes through co-digestion (Tonini et al., 2012), co-incineration (Heller et al., 2004) or gasification (Saez de Bikuña et al., 2016). That is, the vast majority of energy crops are fully removed at the end of their rotation periods. If the assessed energy crops have short-rotation periods (and most of them do, like corn, sugarcane or willow), the grounds to credit any temporary C-sequestration potential beyond SOC gains is questionable (Cherubini et al., 2011). In fact, assuming the frequently harvested biomass as a permanent $\mathrm{C}$ sink during the occupation period may underestimate the real GW impact potential (U.S. EPA, 2010). In their analysis (Figure 2.4-36, page 392), EPA assumes one cut every 3 
years for sugarcane with an average (but constant) C-sequestration equivalent to one-year growth. However, this may contrast sharply with the Brazilian reality of 5 cuts in a 6-year cycle as described in Macedo et al. 2008. Such long-term emission assumptions may dramatically affect reported benefits, resulting in high Csequestration estimations when combined with high productivity crops like sugarcane despite questionably representing reality.

Therefore, if long-term emissions (e.g. from peat oxidation) are not expected, the inventory modeling period in LCA of land-demanding products like biofuels should be restricted to the expected occupation period, so as to be in line with the accuracy, completeness and relevance accounting principles (ISO, 2006b).

\subsection{Dynamic baseline methods for GHG emission accounting from LUC}

Proponents of DBM do not specify the time horizons over which their discounted iLUC factors may be considered. In an endeavour of obtaining 'amortization-free' iLUC emission factors, it is ignored that the occupation time definition is unavoidable in LCA (Martin, 2013). But assuming a dynamic land-use baseline brings more problems. First and foremost, assuming that the global food supply and demand are not reduced in the long-term, the (additional) occupation of arable land is the primary cause that triggers iLUC effects (Kløverpris, 2008; Schmidt et al., 2015). This means that, as long as there is land occupation for energy cropping with food production displaced elsewhere, a cause-effect link (the iLUC causality, see Appendix E.1) is established between the two activities. In other words, the production of this additional food to meet the new demand is linked to the initial land occupation (in terms of carbon and nitrogen flows, as far as GHG emissions are concerned). That is, this iLUC causality link must last as long as land occupation for energy cropping lasts (see Appendix E).

DBMs also discount LUC emissions, which do not need to be reported by those who convert natural land and these will thus remain unaccounted for (see Figures E1 and E2). Not accounting for such emissions implies that the responsibility of the impacts derived cannot be ascribed to anyone and it hence violates the LCA founding polluter-pays principle, as well as the completeness, relevance, transparency and accuracy principles of GHG accounting (Greenhouse Gas Protocol, 2011; ISO, 2006b). 
Second, proponents of DBM take deforestation as a given boundary condition, rather than recognizing it as a consequence of the same or similar (anthropogenic) processes that they assess. This ignores the actual interdependence between the assessed project and the dynamics of the dynamic baseline. The interdependence between the anticipated dynamic baseline and the assessed project lies in the effect that the project will itself increase the reference LUC level for other similar future projects. This is in conflict with the requirement that reference and project must be independent to avoid logical circularity and, practically, leads to the phenomenon that the discounted amount of GHG emissions will increase with the global rate of LUC. Similar mechanisms have been observed in fishery and conservation sciences, where this phenomenon is described as shifting baseline (Papworth et al., 2009; Pauly, 1995). Making the baseline dynamic results in a positive feedback propelling LUC. This is reflected in the low fractions of real LUC GHG emissions that are actually accounted for by the DBMs (see Table 1 and Table E1 and Figure E1 in Appendix E).

Third, rather than a single dynamic land-use baseline (e.g. a dynamic natural regeneration baseline, Milà i Canals et al. 2007; Soimakallio et al. 2015), DBM suggest a double land-use baseline of two different landuse systems (i.e. a natural forest cover in steady-state and an unknown human land-use system) that overlap in time. Consequently, the dynamic land-use baseline cannot be a 'business-as-usual' (BAU) baseline that would apply in a consequential LCA (Soimakallio et al., 2015). BAU are single land-use baselines which are either known (previous land-use) or estimated (marginal land-use) and they are included from year zero (not at year 'one') in the system boundaries of the LCA.

The following analogy illustrates the effect and makes it subject to logical reasoning. Taking regional deforestation trends as dynamic land-use baselines is similar to applying the current GHG emission pattern as dynamic atmospheric baseline to account for the global warming $(\mathrm{GW})$ impacts of additional fossil fuel combustion (Saez de Bikuña et al., 2016). This would mean accepting climate change to happen as a baseline instead of pre-industrial climate conditions that are usually regarded a natural reference for climate change (Hartmann et al., 2013) and the only proven safe climate space for human development (Steffen et al., 2015). Following the dynamic baseline logic, the GHG emissions of burning $1 \mathrm{Mg}$ of additional oil could then be 
considered as "anticipated fossil oil combustion" and accounted as $0.3 \mathrm{Mg} \mathrm{CO}_{2} \mathrm{e}$ (with a GWP of $0.8 \%$, see Figure 1) instead of 34.9 $\mathrm{Mg} \mathrm{CO}_{2} \mathrm{eq}$ (see Appendix F.3).

The above arguments have led us to reject the current DBMs. This brings, however, the amortization problem - and the related the long-term occupation period- into focus again. Amortization of upfront emissions (e.g. from a power plant installation) has not been problematic before, because these tended to be negligible from a life-cycle perspective. LUC are, however, a special type of upfront emissions that have become controversial precisely because of their significant magnitude. It has been shown that early GHG emissions have a more important role in the GW impact of biofuels than later emissions or removals (O'Hare et al., 2009). The amortization of LUC emissions can only be avoided by calculating a time-adjusted GHG emission inventory combined with time-dependent GW characterization factors (Levasseur et al., 2010), but this requires determining the occupation period over which the assessed land will be used. In this respect, the proposed technical criterion to determine the occupation period is dependent on the biorefinery or biofuel type, rather than the practitioner. Therefore, it can minimize the critical role subjects play in determining the environmental impacts of biofuels (Kløverpris and Mueller, 2012; Sanchez et al., 2012).

\subsection{Implications for future LUC modeling and policy-making}

LUC can be seen as the environmental investment that biorefineries and power plants using the feedstock need to pay off through their biofuel production. Ascribing LUC to biorefineries and power-plants could facilitate the tracking of LUC emissions, as it renders the pollution responsibility clearer. This may open the opportunity to legally bind LUC emission reporting to biorefineries and power-plants, which would need to report on a regular (e.g. annual) basis the remaining $\mathrm{C}$ debt (Fargione et al., 2008) they are obliged to pay back. This way, the real $\mathrm{C}$ debt could be calculated and be paid off with the exact amount of biofuel produced/sold. To ensure the claimed benefits of biofuels (from fossil fuel substitution), the total energy demand of the relevant sectors in the country it is consumed must be constant to avoid leakage or rebound effects (Druckman et al., 2011; Hertwich, 2005; Lambin and Meyfroidt, 2011), while cross-checking the Cdebt with an independent accountant or third party. 
Importing energy crops or biofuels from (economically) abandoned land origin poses serious certification challenges. Economically abandoned and marginal lands are contingent and may change with changing social dynamics (subsidies, new cultivars and technology, etc.) (Hatna and Bakker, 2011). However, importing biofuels from physically degraded land (e.g. former tropical forestland in Indonesia that has been invaded by alang-alang grasses) seems more plausible (Searchinger and Ralph, 2015), since those grasslands can be tracked and monitored with satellite imaging systems. For abandoned farmland, it might be more appropriate to incentivize their use whenever a more direct control and monitoring can be established (Pointereau et al., 2008; Terres et al., 2013) and which could be combined with existing relevant policies ((EC), 2003; EEA (European Environment Agency), 2009) to tackle rural depopulation and biodiversity loss.

Even though yield estimates are still needed to compare the environmental performance of biofuels to fossil fuel counterparts in LCA, the main uncertainty source of LUC emission factors in economic models (the yield related parameters) (Plevin et al., 2015) could be avoided. If an accounting or certification system is established that ascribes LUC emissions to companies responsible of the land clearing (measured on site, per ha expanded, or estimated through top-down models), calculated and reported on an area basis instead of an energy (or product) basis (see Table 4). This accounting system would be more in line with a corporate reporting system than a project or product accounting system (Greenhouse Gas Protocol, 2004), and the companies holding the $\mathrm{C}$ debt from LUC would pay it back retrospectively, i.e. with the produced biofuel. These figures would be estimated on the basis of factual, recorded yield data rather than on predicted and uncertain yield estimations.

Moreover, reporting LUC emissions per ha can also avoid possible confusions behind the biofuel emissions' calculations if reported on an energy basis (e.g. LUC reported per energy content - gross energy output - or per useful energy -net energy output), when different technologies are at hand to provide the same service (e.g. heat and power). Under this new perspective, the environmental performance of different land use systems which produce biofuels is assessed (as in e.g. Tonini et al. 2012), rather than biofuel products in itself. 
The lack of transparency behind economic LUC models contributes to their uncertainty, represented by the broad range of results in literature. For instance, it is not clear whether economic iLUC models, despite including intensification effects, always include the related GHG emissions that would derive (directly and indirectly) from an increased used of fertilizers to meet the simulated demand shock (U.S. EPA, 2010; Valin et al., 2015).

The simplicity of top-down models gives them a special advantage over the sophisticated and complex bottom-up models: higher transparency. These can be easily examined, reproduced and updated, contrary to, e.g., the 'black-box' economic LUC models (Broch et al., 2013). Top-down LUC emission factors represent mean $\mathrm{GHG}$ emissions from demanding additional land globally $\left(\mathrm{LUC}_{\text {global }}\right)$ or regionally $\left(\mathrm{LUC}_{\mathrm{GHGP}}\right)$, depicting average agricultural expansion and intensification emissions that new land-demanding products like the studied biofuels generate. Their simple calculation does not impede the inclusion of possible substitution effects (like, e.g., DDGS from corn ethanol) in another step of the assessment. Results could be easily revised periodically with updated land-use cover and synthetic-N production statistics, while their uncertainties would mainly relate to $\mathrm{C}$ stock estimates of the affected land areas. Despite being less representative of the product-specific LUC effect than bottom-up models (e.g. $\mathrm{LUC}_{\text {global }}$ does not differentiate between demanding corn or wheat, in China or in US), top-down models can provide an external reference system for a rough validation of bottom-up LUC estimates (e.g. they can provide a scale reference to determine the right order of magnitude of LUC emission estimates). Such top-down LUC models can theoretically converge to (and in the limit coincide with) national and global LUC emission statistics and thus be a way to reconcile bottom-up assessments (Creutzig et al., 2012), providing complementary information for regulation and policy-making (European Commission, 2015). The authors recognize that deforestation and LUC phenomena are intricate processes which involves several actors and which spans over several years (Gaveau et al., 2016). Nevertheless, top-down LUC factors can be a way to set the mean of regional and global LUC emissions by taking a broad landscape approach and by simplifying a complex issue that requires urgent action. 


\section{Conclusions}

Different methods have been investigated to explore their advantages and disadvantages in the accounting of GHG emissions from LUC in biofuel LCAs. To ensure result harmonization, the different time horizons involved in LCA have been defined and the methods have been applied to four known biofuel study cases. The main findings of the study can be summarized as follows:

- Six different time horizons (technological scope, inventory model, impact characterization, amortization/occupation, plantation lifetime, harvesting frequency) can and should be distinguished when performing an LCA of land-demanding products. Apart from the impact characterization, the other time horizons can be defined according to an exclusively technical criterion. It is of crucial importance to agree, first, on their definitions and secondly, on their values (for LCA studies of same biofuels/products), to allow full comparability and foster high quality environmental footprinting standards.

- The reasons behind systematic underestimations (dynamic land-use baselines and high Csequestration assumptions) and overestimations (exclusion of intensification effects) of LUC emissions were identified. In this regard, the validity of the large discounting (99\%) applied by current DBM to account for deforestation emissions is disputed. Even though the amortization of LUC emissions can be avoided with time-adjusted GHG inventory and GWP characterization factors, defining the inventory modeling period (i.e. land occupation period) cannot. This is an intrinsic part of the system boundaries of any LCA dealing with land-demanding products and the cut-off criterion should be clearly stated in the scope phase.

- The technical lifetime of biorefineries or power-plants (technological scope) in LCA of landdemanding biofuels is proposed as the best proxy for this cut-off criterion, which it is claimed to represent the long-term occupation of the land used for the production of feedstock. This is a purely technical -thus robust-criterion, valid to determine both the amortization (if performed) and inventory modeling periods. This is in line with common economic practice in industry for the 
amortization of investments and the calculation of the net present value, thus used for project management and decision-making.

- Calculating LUC emissions per ha and legally binding them to companies responsible for the agricultural land expansion could avoid the uncertainty related to yield estimation in LUC emission estimates.

- Top-down models represent average LUC emissions at different spatial resolutions derived from deforestation statistics. Their results can serve as a rough validation reference for bottom-up LUC emission estimates, being complementary rather than competitors for decision-support and policymaking.

\section{Acknowledgements}

The authors would like Davide Tonini, for the long discussions and the valuable input he provided.

\section{References}

(EC), E.C., 2003. Common rules for direct support schemes under the common agricultural policy and establishing certain support schemes for farmers.

Bakas, I., Hauschild, M.Z., Astrup, T.F., Rosenbaum, R.K., 2015. Preparing the ground for an operational handling of long-term emissions in LCA. Int. J. Life Cycle Assess. 20, 1444-1455. doi:10.1007/s11367-015-0941-4

Brandão, M., Canals, L.M., 2012. Global characterisation factors to assess land use impacts on biotic production. Int. J. Life Cycle Assess. 18, 1243-1252. doi:10.1007/s11367-012-0381-3

Broch, A., Hoekman, S.K., Unnasch, S., 2013. A review of variability in indirect land use change assessment and modeling in biofuel policy. Environ. Sci. Policy 29, 147-157. doi:10.1016/j.envsci.2013.02.002

BSI, 2011. PUBLICLY AVAILABLE SPECIFICATION: PAS 2050:2011. Specification for the assessment of the life cycle greenhouse gas emissions of goods and services. British Standards Institution, London.

Cherubini, F., Bird, N.D., Cowie, A., Jungmeier, G., Schlamadinger, B., Woess-Gallasch, S., 2009. Energyand greenhouse gas-based LCA of biofuel and bioenergy systems: Key issues, ranges and recommendations. Resour. Conserv. Recycl. 53, 434-447. doi:10.1016/j.resconrec.2009.03.013

Cherubini, F., Peters, G.P., Berntsen, T., Strømman, A.H., Hertwich, E., 2011. CO2 emissions from biomass combustion for bioenergy: atmospheric decay and contribution to global warming. GCB Bioenergy 3 , 413-426. doi:10.1111/j.1757-1707.2011.01102.x

Cintas, O., Berndes, G., Cowie, A.L., Egnell, G., Holmström, H., Ågren, G.I., 2015. The climate effect of increased forest bioenergy use in Sweden: evaluation at different spatial and temporal scales. Wiley Interdiscip. Rev. Energy Environ. n/a-n/a. doi:10.1002/wene.178 
Creutzig, F., Popp, A., Plevin, R., Luderer, G., Minx, J., Edenhofer, O., 2012. Reconciling top-down and bottom-up modelling on future bioenergy deployment. Nat. Clim. Chang. 2, 320-327. doi:10.1038/nclimate1416

Davis, R., Tao, L., Tan, E.C.D., Biddy, M.J., Beckham, G.T., Scarlata, C., Jacobson, J., Cafferty, K., Ross, J., Lukas, J., Knorr, D., Schoen, P., 2013. Process Design and Economics for the Conversion of Lignocellulosic Biomass to Hydrocarbons: Dilute-Acid and Enzymatic Deconstruction of Biomass to Sugars and Biological Conversion of Sugars to Hydrocarbons. doi:10.2172/1107470

Druckman, A., Chitnis, M., Sorrell, S., Jackson, T., 2011. Missing carbon reductions? Exploring rebound and backfire effects in UK households. Energy Policy 39, 3572-3581. doi:10.1016/j.enpol.2011.03.058

EEA (European Environment Agency), 2009. Distribution and targeting of the CAP budget from a biodiversity perspective. doi:10.2800/30605

Energinet, 2012. TECHNOLOGY DATA FOR ENERGY PLANTS. The Danish Energy Agency and the Danish Ministry of Energy, Copenhagen.

European Commission, 2015. DIRECTIVE 2015/1513 OF THE EUROPEAN PARLIAMENT AND OF THE COUNCIL. Off. J. Eur. Union 19, 1-29.

European Commission, 2009. Directive 2009/28/EC of the European Parliament and of the Council of 23 April 2009. Off. J. Eur. Union 140, 16-62. doi:10.3000/17252555.L_2009.140.eng

Fargione, J., Hill, J., Tilman, D., Polasky, S., Hawthorne, P., 2008. Land clearing and the biofuel carbon debt. Science 319, 1235-1238. doi:10.1126/science. 1152747

Finkbeiner, M., 2014. Indirect land use change - Help beyond the hype? Biomass and Bioenergy 62, 218221. doi:10.1016/j.biombioe.2014.01.024

Gaveau, D.L.A., Sheil, D., Husnayaen, Salim, M.A., Arjasakusuma, S., Ancrenaz, M., Pacheco, P., Meijaard, E., 2016. Rapid conversions and avoided deforestation: examining four decades of industrial plantation expansion in Borneo. Sci. Rep. 6, 32017. doi:10.1038/srep32017

Greenhouse Gas Protocol, 2011. Product life cycle accounting and reporting standard. World Resource Institute and World Business Council for Sustainable Development. doi:10.1017/CBO9781107415324.004

Greenhouse Gas Protocol, 2004. Greenhouse Gas Protocol - A Corporate Accounting and Reporting Standard, Greenhouse Gas Protocol. World Resource Institute and World Business Council for Sustainable Development. doi:1569735689

Haberl, H., Beringer, T., Bhattacharya, S.C., Erb, K.-H., Hoogwijk, M., 2010. The global technical potential of bio-energy in 2050 considering sustainability constraints. Curr. Opin. Environ. Sustain. 2, 394-403. doi:10.1016/j.cosust.2010.10.007

Haberl, H., Sprinz, D., Bonazountas, M., Cocco, P., Desaubies, Y., Henze, M., Hertel, O., Johnson, R.K., Kastrup, U., Laconte, P., Lange, E., Novak, P., Paavola, J., Reenberg, A., van den Hove, S., Vermeire, T., Wadhams, P., Searchinger, T., 2012. Correcting a fundamental error in greenhouse gas accounting related to bioenergy. Energy Policy 45, 18-23. doi:10.1016/j.enpol.2012.02.051

Hartmann, D.L., Tank, a. M.G.K., Rusticucci, M., 2013. IPCC Fifth Assessment Report, Climatie Change 2013: The Physical Science Basis. Ipcc AR5, 31-39.

Hatna, E., Bakker, M.M., 2011. Abandonment and Expansion of Arable Land in Europe. Ecosystems 14, 720-731. doi:10.1007/s10021-011-9441-y 
Hauschild, M., Olsen, S.I., Hansen, E., Schmidt, A., 2008. Gone...but not away - Addressing the problem of long-term impacts from landfills in LCA. Int. J. Life Cycle Assess. 13, 547-554. doi:10.1007/s11367008-0039-3

Heller, M.C., Keoleian, G. a, Mann, M.K., Volk, T. a, 2004. Life cycle energy and environmental benefits of generating electricity from willow biomass. Renew. Energy 29, 1023-1042. doi:10.1016/j.renene.2003.11.018

Hertwich, E.G., 2005. Consumption and the rebound effect: An industrial ecology perspective. J. Ind. Ecol. 9, 85-98. doi:10.1162/1088198054084635

IPCC, 2006. 2006 IPCC Guidelines for National Greenhouse Gas Inventories, 2006 IPCC Guidelines for National Greenhouse Gas Inventories. Institute for Global Environmental Strategies (IGES), Japan.

ISO, 2013. ISO 14067:2013 Greenhouse gases - Carbon footprint of products - Requirements and guidelines for quantification and communication, International Organization for Standardization. International Organization for Standardization, Geneva, Switzerland.

ISO, 2006a. ISO 14040: Environmental management — Life Cycle Assessment — Principles and Framework, International Organization for Standardization. International Organization for Standardization, Geneva, Switzerland. doi:10.1002/jtr

ISO, 2006b. ISO 14044: Environmental management — Life cycle assessment — Requirements and guidelines, International Organization for Standardization. International Organization for Standardization, Geneva, Switzerland. doi:10.1136/bmj.332.7555.1418

Kløverpris, J.H., 2008. Consequential Life Cycle Inventory modelling of Land Use induced by crop consumption. PhD Thesis. Technical University of Denmark. doi:10.1007/s11367-009-0132-2

Kløverpris, J.H., Mueller, S., 2013. Baseline time accounting--reply to the letter to the editor of Martin [Int J Life Cycle Assess (2013) 18(7):1279]. Int. J. Life Cycle Assess. 19, 257-259. doi:10.1007/s11367-0130656-3

Kløverpris, J.H., Mueller, S., 2012. Baseline time accounting: Considering global land use dynamics when estimating the climate impact of indirect land use change caused by biofuels. Int. J. Life Cycle Assess. 18, 319-330. doi:10.1007/s11367-012-0488-6

Lambin, E.F.E., Meyfroidt, P., 2011. Global land use change, economic globalization, and the looming land scarcity. Proc. Natl. Acad. Sci. U. S. A. 108, 3465-3472. doi:10.1073/pnas.1100480108

Lapola, D.M., Schaldach, R., Alcamo, J., Bondeau, A., Koch, J., Koelking, C., Priess, J. a, 2010. Indirect land-use changes can overcome carbon savings from biofuels in Brazil. Proc. Natl. Acad. Sci. U. S. A. 107, 3388-93. doi:10.1073/pnas.0907318107

Levasseur, A., Lesage, P., Margni, M., Deschěnes, L., Samson, R., 2010. Considering time in LCA: Dynamic LCA and its application to global warming impact assessments. Environ. Sci. Technol. 44, 3169-3174. doi:10.1021/es9030003

Li, W., Ciais, P., Wang, Y., Peng, S., Broquet, G., Ballantyne, A.P., Canadell, J.G., Cooper, L.A., Friedlingstein, P., Le Quéré, C., Myneni, R.B., Peters, G., Piao, S., Pongratz, J., 2016. Reducing uncertainties in decadal variability of the global carbon budget with multiple data sets. Proc. Natl. Acad. Sci. U. S. A. accepted. doi:10.1073/pnas.1603956113

Macedo, I.C., Seabra, J.E.A., Silva, J.E.A.R., 2008. Green house gases emissions in the production and use of ethanol from sugarcane in Brazil: The 2005/2006 averages and a prediction for 2020. Biomass and Bioenergy 32, 582-595. doi:10.1016/j.biombioe.2007.12.006 
Martin, J.I., 2013. Regarding your article "Baseline time accounting: considering global land use dynamics when estimating the climate impact of indirect land use change caused by biofuels." Int J Life Cycle Assess 18(2):319-330. doi: 10.1007/s11367-012-0488-6. Int. J. Life Cycle Assess. 18, 1279-1279.

Milà i Canals, L., Bauer, C., Depestele, J., Dubreuil, A., Knuchel, R.F., 2007. Key Elements in a Framework for Land Use Impact Assessment Within LCA. Int. J. Life cycle Assess. 12, 5-15.

Milà i Canals, L., Rigarlsford, G., Sim, S., 2012. Land use impact assessment of margarine. Int. J. Life Cycle Assess. 18, 1265-1277. doi:10.1007/s11367-012-0380-4

Muñoz, I., Schmidt, J.H., Brandão, M., Weidema, B.P., 2014. Rebuttal to "Indirect land use change (iLUC) within life cycle assessment (LCA) - scientific robustness and consistency with international standards.” GCB Bioenergy n/a-n/a. doi:10.1111/gcbb.12231

O’Hare, M., Plevin, R.J., Martin, J.I., Jones, A.D., Kendall, A., Hopson, E., 2009. Proper accounting for time increases crop-based biofuels' greenhouse gas deficit versus petroleum. Environ. Res. Lett. 4, 24001. doi:10.1088/1748-9326/4/2/024001

Papworth, S.K., Rist, J., Coad, L., Milner-Gulland, E.J., 2009. Evidence for shifting baseline syndrome in conservation. Conserv. Lett. 2, 93-100. doi:10.1111/j.1755-263X.2009.00049.x

Pauly, D., 1995. Anecdotes and the shifting baseline syndrome of fisheries. Trends Ecol. Evol. doi:10.1016/S0169-5347(00)89171-5

Pawelzik, P., Carus, M., Hotchkiss, J., Narayan, R., Selke, S., Wellisch, M., Weiss, M., Wicke, B., Patel, M.K., 2013. Critical aspects in the life cycle assessment (LCA) of bio-based materials - Reviewing methodologies and deriving recommendations. Resour. Conserv. Recycl. 73, 211-228. doi:10.1016/j.resconrec.2013.02.006

Plevin, R.J., Beckman, J., Golub, A.A., Witcover, J., O’Hare, M., 2015. Carbon Accounting and Economic Model Uncertainty of Emissions from Biofuels-Induced Land Use Change. Environ. Sci. Technol. 49, 2656-2664. doi:10.1021/es505481d

Plevin, R.J., Jones, A.D., Torn, M.S., Group, R., Division, E.S., Berkeley, L., 2010. The greenhouse gas emissions from indirect land use change are uncertain, but potentially much greater than previously estimated. Environ. Sci. Technol. 44, 8015-8021.

Pointereau, P., Coulon, F., Girard, P., Lambotte, M., Stuczynski, T., Sánchez Ortega, V., Del Rio, A., 2008. Analysis of farmland abandonment and the extent and location of agricultural areas that are actually abandoned or are in risk to be abandoned. Inst. Environ. Sustain. (Joint Res. Centre).

Reijnders, L., Huijbregts, M. a. J., 2008. Biogenic greenhouse gas emissions linked to the life cycles of biodiesel derived from European rapeseed and Brazilian soybeans. J. Clean. Prod. 16, 1943-1948. doi:10.1016/j.jclepro.2008.01.012

Saez de Bikuña, K., Hauschild, M.Z., Pilegaard, K., Ibrom, A., 2016. Environmental performance of gasified willow from different lands including land-use changes. GCB Bioenergy. doi:10.1111/gcbb.12378

Sanchez, S.T., Woods, J., Akhurst, M., Brander, M., O’Hare, M., Dawson, T.P., Edwards, R., Liska, A.J., Malpas, R., 2012. Accounting for indirect land-use change in the life cycle assessment of biofuel supply chains. J. R. Soc. Interface 9, 1105-19. doi:10.1098/rsif.2011.0769

Schmidt, J.H., Weidema, B.P., Brandão, M., 2015. A Framework for Modelling Indirect Land Use Changes in Life Cycle Assessment. J. Clean. Prod. 99, 230-238. doi:10.1016/j.jclepro.2015.03.013

Schwartz, P., 2005. The polluter-pays principle. Res. Handb. Int. Environ. Law 243-261. 
Seabra, J.E.A., Macedo, I.C., Chum, H.L., Faroni, C.E., Sarto, C.A., 2011. Life cycle assessment of Brazilian sugarcane products: GHG emissions and energy use. Biofuels, Bioprod. Biorefining 5, 519-532. doi:10.1002/bbb.289

Searchinger, T., Heimlich, R., Houghton, R. a, Dong, F., Elobeid, A., Fabiosa, J., Tokgoz, S., Hayes, D., Yu, T.-H., 2008. Use of U.S. croplands for biofuels increases greenhouse gases through emissions from land-use change. Science 319, 1238-40. doi:10.1126/science.1151861

Searchinger, T., Ralph, H., 2015. Avoiding Bioenergy Competition for Food Crops and Land, World resources Institute.

Searchinger, T.D., Hamburg, S.P., Melillo, J., Chameides, W., Havlik, P., Kammen, D.M., Likens, G.E., Lubowski, R.N., Obersteiner, M., Oppenheimer, M., Robertson, G.P., Schlesinger, W.H., Tilman, G.D., 2009. Fixing a critical climate accounting error. Science 326, 527-528. doi:10.1126/science. 1178797

Smith, P., Bustamante, M., Ahammad, H., Clark, H., Dong, H., Elsiddig, E.A., Haberl, H., Harper, R., House, J., Jafari, M., Masera, O., Mbow, C., Ravindranath, N.H., Rice, C.W., Robledo Abad, C., Romanovskaya, A., Sperling, F., Tubiello, F., 2014. Agriculture, Forestry and Other Land Use (AFOLU), in: Climate Change 2014: Mitigation of Climate Change. Contribution of Working Group III to the Fifth Assessment Report of the Intergovernmental Panel on Climate Change. [Edenhofer, O., R. Pichs-Madruga, Y. Sokona, E. Farahani, S. Kadner, K. Seyboth, A. Adler. IPCC, Geneva, Switzerland, pp. 811-922.

Soimakallio, S., Cowie, A., Brandão, M., Finnveden, G., Ekvall, T., Erlandsson, M., Koponen, K., Karlsson, P.-E., 2015. Attributional life cycle assessment: is a land-use baseline necessary? Int. J. Life Cycle Assess. 20, 1364-1375. doi:10.1007/s11367-015-0947-y

Steffen, W., Richardson, K., Rockström, J., Cornell, S., Fetzer, I., Bennett, E., Biggs, R., Carpenter, S., 2015. Planetary boundaries: Guiding human development on a changing planet. Science 348, 1217. doi:10.1126/science.aaa9629

Terres, J.M., Nisini, L., Anguiano, E., 2013. Assessing the risk of farmland abandonment in the EU. doi:10.2788/81337

The Greenhouse Gas Protocol, 2006. The Land Use, Land-Use Change, and Forestry Guidance for GHG Project Accounting, Greenhouse Gas Protocol. World Resource Institute, Washington.

Tonini, D., Hamelin, L., Astrup, T.F., 2016. Environmental implications of the use of agro-industrial residues for biorefineries: application of a deterministic model for indirect land-use changes. GCB Bioenergy 8, 690-706. doi:10.1111/gcbb.12290

Tonini, D., Hamelin, L., Wenzel, H., Astrup, T., 2012. Bioenergy production from perennial energy crops: a consequential LCA of 12 bioenergy scenarios including land use changes. Environ. Sci. Technol. 46, 13521-30. doi:10.1021/es3024435

U.S. Congress, 2005. Energy Policy Act, Public Law 109-58.

U.S. Environmental Protection Agency (EPA), 2010. Renewable Fuel Standard Program (RFS2) Regulatory Impact Analysis. Publication EPA-420-R-10-006. doi:EPA-420-R-10-006., February 2010

UNEP/SETAC Life Cycle Initiative, 2016. Global Guidance For Life Cycle Impact Assessment Indicators. Volume 1. doi:978-92-807-3630-4

Valin, H., Peters, D., van den Berg, M., Frank, S., Havlík, P., Forsell, N., Hamelinck, C., 2015. The land use 
Warner, E., Zhang, Y., Inman, D., Heath, G., 2014. Challenges in the estimation of greenhouse gas emissions from biofuel-induced global land-use change. Biofuels, Bioprod. Biorefining. doi:10.1002/bbb.1434

Wicke, B., Dornburg, V., Junginger, M., Faaij, A., 2008. Different palm oil production systems for energy purposes and their greenhouse gas implications. Biomass and Bioenergy 32, 1322-1337. doi:10.1016/j.biombioe.2008.04.001 